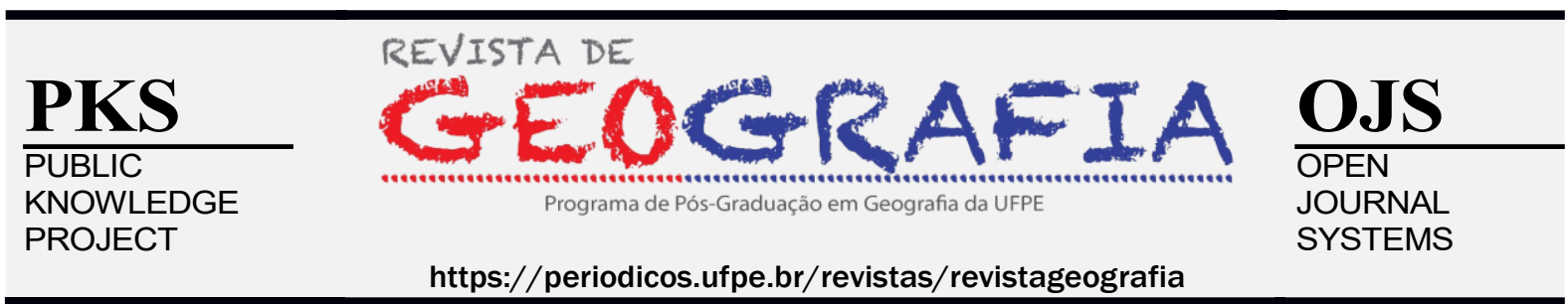

\title{
O PAPEL DO ESTADO E DO CAMPESINATO NA CONDUÇÃO DE POLÍTICAS PÚBLICAS PARA A PRODUÇÃO E A COMERCIALIZAÇÃO CAMPONESA: ANÁLISE A PARTIR DOS CIRCUITOS CURTOS DE COMERCIALIZAÇÃO
}

\begin{abstract}
Simone Maria Leme ${ }^{1}$
${ }^{1}$ Professora do Instituto Federal de Mato Grosso do Sul (IFMS). Doutora em Geografia pela Universidade Federal da Grande Dourados - MS (UFGD). E-mail: simone.leme@ifms.edu.br. ORCID: https://orcid.org/00000002-1273-0639
\end{abstract}

Artigo recebido em 06/07/2021 e aceito em 18/09/2021

\begin{abstract}
RESUMO
Neste artigo, pretende-se discutir o papel do Estado e do campesinato na condução de políticas públicas para a produção e a comercialização camponesa. A participação do campesinato na produção de alimentos é um tema debatido por muitos autores que analisam a reprodução camponesa no capitalismo. As estratégias de comercialização dos produtos do campesinato são instrumentos importantes para a reprodução desses sujeitos sociais, enquanto classe, que lutam constantemente para permanecer na terra de trabalho. A participação do campesinato em circuitos curtos de comercialização garante a reprodução deles, mediante a geração de renda, considerando a venda direta no mercado local. Esse mecanismo também colabora para alcançar a chamada soberania alimentar, tendo em vista a garantia do direito de produção de alimentos para o autoconsumo da família camponesa e a venda no mercado local. No Brasil, as políticas públicas para o campo privilegiam grandes grupos econômicos, em detrimento dos camponeses. Assim sendo, somente a partir da ação política de movimentos camponeses tem-se a criação de leis e programas destinados ao campo. Apreende-se que o Estado, na formulação de suas políticas, exclui qualquer possibilidade de atendimento ao campesinato. Dessa forma, a principal reivindicação dos movimentos é por ações do poder público. Porém, o Estado pode criar meios para combater os movimentos, provocando a diminuição ou a extinção de suas ações. Entende-se que mesmo em momentos de repressão das lutas camponesas, esses sujeitos sociais são capazes de desenvolver várias estratégias para seu contínuo processo de reprodução.
\end{abstract}

Palavras-chave: Políticas públicas; Circuitos curtos de comercialização; Soberania alimentar; Estratégias de reprodução camponesa.

\section{THE ROLE OF THE STATE AND THE PEASANTRY IN THE CONDUCTION OF PUBLIC POLICIES FOR PEASANT PRODUCTION AND COMMERCIALIZATION: ANALYSIS FROM THE SHORT COMMERCIALIZATION CIRCUITS}

\section{ABSTRACT}

In this article, it is intended to discuss the role of the State and the peasantry in conducting public policies for peasant production and commercialization. The participation of peasants in food production is a theme debated by many authors who analyze peasant reproduction in capitalism. Strategies for the 
commercialization of peasant products are essential instruments for the reproduction of these social subjects, as a social class, who are constantly struggling to remain on the labor land. The participation of peasants in short commercialization circuits ensures their reproduction, based on income generation, considering the direct sale in the local market. This mechanism also collaborates to achieve food sovereignty, considering the guarantee of the right to produce food for the peasant family's consumption and sale in the local market. In Brazil, public policies for the rural areas favor large economic groups over peasants. Therefore, it is only through the political action of peasant movements that laws and programs destined for the rural areas have been created. It is understood that the State, in the formulation of its policies, excludes any possibility of assisting peasants. In this way, the main claim of the movements is for public policies. However, the State could create means to combat the movements, thus provoking the reduction or extinction of their actions. It is understood that even in moments of repression of peasant struggles, these social subjects are capable of developing several strategies for their continuous reproduction process.

Keywords: Public policies. Short commercialization circuits. Food sovereignty. Peasant reproduction strategies.

\title{
EL PAPEL DEL ESTADO Y DEL CAMPESINADO EN LA CONDUCCIÓN DE LAS POLÍTICAS PÚBLICAS DE PRODUCCIÓN Y COMERCIALIZACIÓN CAMPESINA: ANÁLISIS DESDE LOS CIRCUITOS CORTOS DE COMERCIALIZACIÓN
}

\begin{abstract}
RESUMEN
Este artículo pretende discutir el papel del Estado y del campesinado en la conducción de las políticas públicas de producción y comercialización campesina. La participación de los campesinos en la producción de alimentos es un tema debatido por muchos autores que analizan la reproducción campesina en el capitalismo. Las estrategias de comercialización de los productos campesinos son instrumentos importantes para la reproducción de estos sujetos sociales, como clase, que luchan constantemente por permanecer en la tierra de trabajo. La participación de los campesinos en los circuitos cortos de comercialización asegura su reproducción mediante la generación de ingresos, considerando la venta directa en el mercado local. Este mecanismo también colabora para lograr la llamada soberanía alimentaria, considerando la garantía del derecho a producir alimentos para el propio consumo de la familia campesina y la venta en el mercado local. En Brasil, las políticas públicas para el campo favorecen a los grandes grupos económicos, en detrimento de los campesinos. Así, sólo a través de la acción política de los movimientos campesinos son hechas leyes y programas para el campo. Se comprende que el Estado, al formular sus políticas, excluya toda posibilidad de atender a los campesinos. Por lo tanto, la principal reivindicación de los movimientos es por acciones del poder público. Sin embargo, el Estado puede crear medios para luchar contra los movimientos, provocando la reducción o extinción de sus acciones. Se entiende que aún en tiempos de represión de las luchas campesinas, estos sujetos sociales son capaces de desarrollar diversas estrategias para su continuo proceso de reproducción.
\end{abstract}

Palabras clave: Políticas públicas. Circuitos cortos de comercialización. Soberanía alimentaria. Estrategias de reproducción de los campesinos. 


\section{INTRODUÇÃO}

A questão agrária é um problema estrutural do desenvolvimento desigual e contraditório do capitalismo no campo, que permite a criação e a recriação de relações não capitalistas de produção (campesinato), subordinando-as ao seu processo de desenvolvimento (OLIVEIRA, 1991, 1999; MARTINS, 1990). Os conflitos no campo brasileiro resultam das disputas por frações territoriais entre classes sociais com interesses antagônicos (capitalistas e camponeses). A histórica estrutura fundiária concentrada (Tabela 1) e as alianças realizadas entre o Estado e o capital são os norteadores principais desses conflitos.

Ao analisar a Tabela 1, verificam-se as características da estrutura fundiária brasileira registrada no Censo Agropecuário de 2017 (IBGE, 2018). Percebe-se que a agricultura familiar camponesa ocupa uma pequena parcela do território, porém é representativa em número de estabelecimentos: tem-se 4.596.277 estabelecimentos agropecuários de até 50 hectares (ha), que ocupam uma área de pouco mais de $5 \%$ da área total dos estabelecimentos agropecuários. Propriedades com mais de 1000 ha (50.865) ocupam uma área de 47,52\% da área total dos estabelecimentos agropecuários.

A grande expansão do agronegócio nas últimas décadas deixa clara a aliança Estadocapital. No Brasil, tem-se consideráveis extensões de terras sendo utilizadas para o cultivo de uma única cultura, voltada para atender o mercado agroexportador. Nesse processo de expansão capitalista ocorre a expropriação do campesinato e o aumento da população urbana, o que implica de forma imediata o modo de viver das pessoas, no campo e nas cidades.

Tabela 1 - Brasil

Número e área dos estabelecimentos agropecuários, por grupo de área (2017)

\begin{tabular}{l|r|r|r}
\multicolumn{1}{c}{ Grupos de área } & $\begin{array}{c}\text { Número de } \\
\text { estabelecimentos }\end{array}$ & $\begin{array}{c}\text { Área dos } \\
\text { estabelecimentos }\end{array}$ & \multicolumn{1}{c}{ \% da área total } \\
\hline Mais de 0 até menos de 10 ha & 3.010 .311 & 7.989 .114 & 2,28 \\
\hline De 10 a menos de 20 ha & 730.405 & 10.202 .129 & 2,91 \\
\hline De 20 a menos de 50 ha & 855.561 & 26.652 .077 & 7,60 \\
\hline De 50 a menos de 100 ha & 393.949 & 26.929 .140 & 21,16 \\
\hline De 100 a menos de 500 ha & 365.453 & 74.164 .629 & 10,81 \\
\hline De 500 a menos de 1000 ha & 54.683 & 37.864 .983 & 47,52 \\
\hline Acima de 1000 ha & 50.865 & 166.451 .258 & - \\
\hline Produtor sem área & 76.671 & 350.253 .329 & 100 \\
\hline Total & 5.072 .152 & - & \\
\hline
\end{tabular}

Fonte: Organizada pela autora com base em IBGE (2018).

Porém, a classe camponesa se ergue contra o crescimento do capitalismo no campo. A partir da atuação dos movimentos sociais, esses sujeitos realizam ocupações de terra com o 
objetivo de forçar o Estado a realizar a reforma agrária. Assim, há dois modelos de desenvolvimento distintos para o campo: o da agricultura familiar camponesa e o do agronegócio (FERNANDES, 2015).

A aliança entre Estado e classe dominante já foi teorizada por Marx e Engels (1998a), que afirmaram que o primeiro atende o interesse de determinada classe social (dominante). $\mathrm{O}$ Estado é uma comunidade ilusória dos homens, pois, atrás das concepções ideológicas, ele está sempre vinculado a uma classe dominante. Portanto, as lutas de classes devem ser travadas contra o Estado.

Dessa forma, as políticas públicas que atendem determinada classe social, não dominante, somente serão conquistadas com lutas políticas. Um exemplo são as conquistas trabalhistas: todos os direitos dos trabalhadores até hoje conquistados no Brasil foram estabelecidos pela organização da classe trabalhadora em sindicatos e movimentos reivindicatórios; nada é conquistado sem esforço. Como muito bem pontuado por Marx e Engels (1998b, p. 40), "a história de todas as sociedades até hoje existentes é a história das lutas de classe".

Posto isso, neste artigo pretende-se discutir o papel do Estado e do campesinato na condução de políticas públicas para a produção e a comercialização camponesa. A participação do campesinato na produção de alimentos é um tema debatido por muitos autores que se propõem a discutir a reprodução camponesa em meio ao desenvolvimento do capitalismo no campo. Dessa forma, as estratégias de comercialização dos produtos do campesinato são instrumentos importantes para a reprodução desses sujeitos sociais, enquanto classe, que lutam constantemente para permanecer na terra de trabalho.

A participação do campesinato em circuitos curtos de comercialização garante a reprodução camponesa, a partir da geração de renda, considerando a venda direta no mercado local. Esse mecanismo também colabora para alcançar a chamada soberania alimentar, tendo em vista a garantia do direito de produção de alimentos para o autoconsumo da família camponesa e a venda no mercado local, reduzindo, assim, a dependência de produtos de outras regiões ou de outros países.

Este artigo está estruturado em três tópicos principais. Inicialmente, será discutida a definição de circuitos curtos de comercialização e a importância desses circuitos para a reprodução do campesinato. Na sequência, aborda-se a relevância do desenvolvimento dos circuitos curtos de comercialização para promover a soberania alimentar dos povos. E, para 
finalizar, debate-se o papel do Estado e do campesinato na condução de políticas públicas para a produção e a comercialização camponesa, considerando a importância dos circuitos curtos na comercialização dos produtos do campesinato.

\section{OS CIRCUITOS CURTOS DE COMERCIALIZAÇÃO E A REPRODUÇÃO SOCIAL DO CAMPESINATO}

Os circuitos curtos de comercialização são um modelo de produção e consumo desenvolvido em escala local. Para Darolt (2013), no Brasil, não há uma concepção oficial para os circuitos curtos de comercialização. Na França, esses circuitos são conceituados como aqueles que mobilizam até um intermediário entre o produtor e o consumidor. Dois casos distintos podem ser caracterizados como circuitos curtos de comercialização:

[...] a venda direta (quando o produtor entrega em mãos próprias a mercadoria ao consumidor) e a venda via um único intermediário (que pode ser um outro produtor, uma cooperativa, uma associação, uma loja especializada, um restaurante ou até um pequeno supermercado local) (DAROLT, 2013, p. 142).

Baptista et al. (2013), a partir de estudos realizados em Portugal, também definem os circuitos curtos como um modelo de comercialização em que ocorre a venda direta do produtor ao consumidor; ou indireta, mediante a presença de, no máximo, um intermediário. Esses autores também se utilizam da associação de uma maior proximidade geográfica entre produtores e consumidores. Eles destacam as seguintes características desse tipo de circuito:

- identificação das características do local no produto (alguns itens com etiquetas trazem consigo aspectos locais e do modo de vida do campesinato);

- o produtor, além de produzir, realiza as atividades de beneficiamento e comercialização dos produtos (valorização do saber-fazer local);

- utilizam matérias-primas locais para a produção;

- o consumidor tem acesso a informações sobre produto, origem, modo de produção e sua qualidade;

- a comunicação entre produtores e consumidores permite criar confiança mútua e diferenciar os produtos locais dos restantes (nas feiras livres, é muito comum camponeses produzirem mercadorias que atendam uma determinada clientela, por exemplo: fazer queijo com uma 
menor quantidade de sal, ou colocar temperos específicos; esse tipo de produção é realizada sob encomenda).

Nas Figuras 1 e 2, ilustram-se embalagens de farinha de mandioca produzida de forma tradicional em comunidade camponesa do município de Anastácio-MS. As imagens da Figura 3 mostram espaços de comercialização direta na mesma cidade.

Figura 1 - Anastácio-MS

Embalagens com farinha de mandioca produzida na Colônia Pulador (2018)

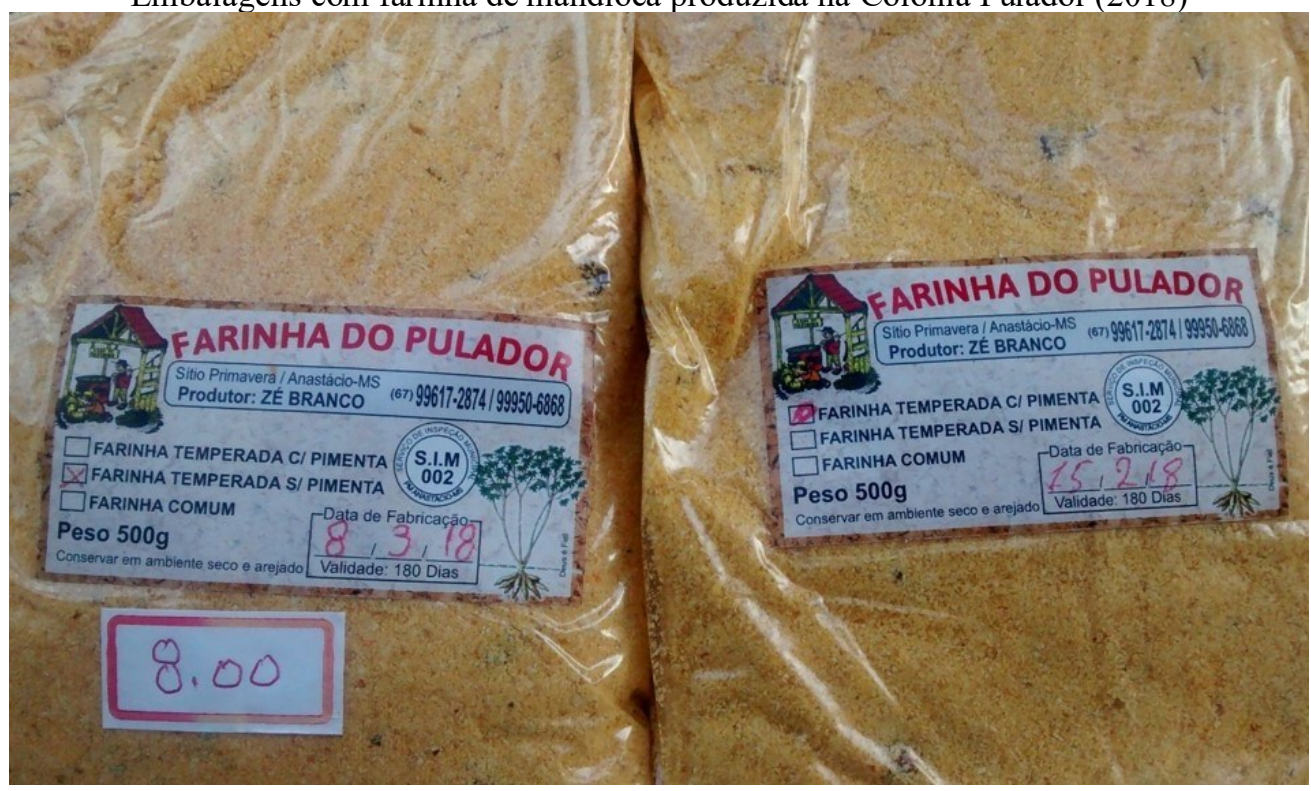

Fonte: Imagem capturada pela autora.

Figura 2 - Anastácio-MS

Embalagens com farinha de mandioca produzida na Colônia Pulador (2019)

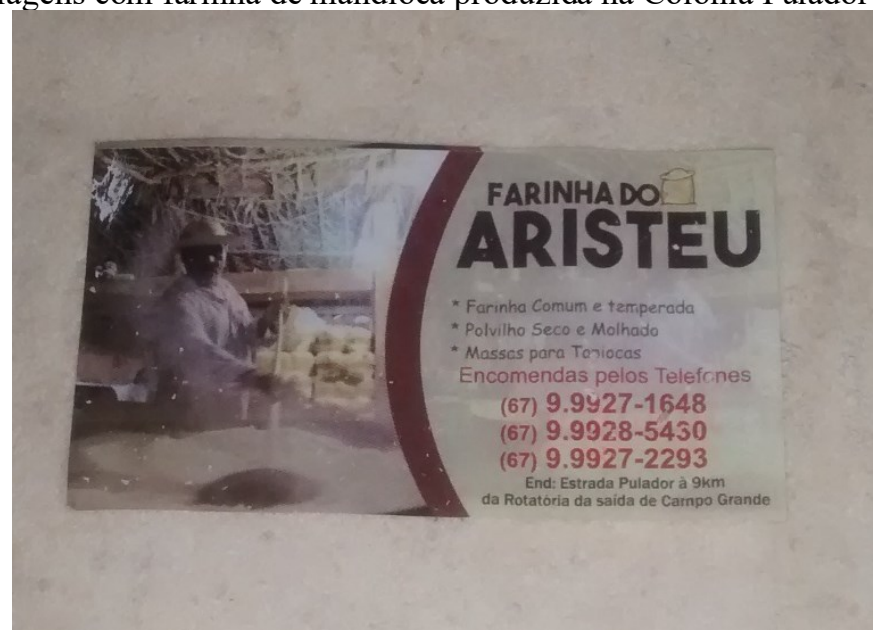

Fonte: Imagem capturada pela autora. 
Figura 3 - Anastácio-MS

Espaços de comercialização direta (2018/2019)

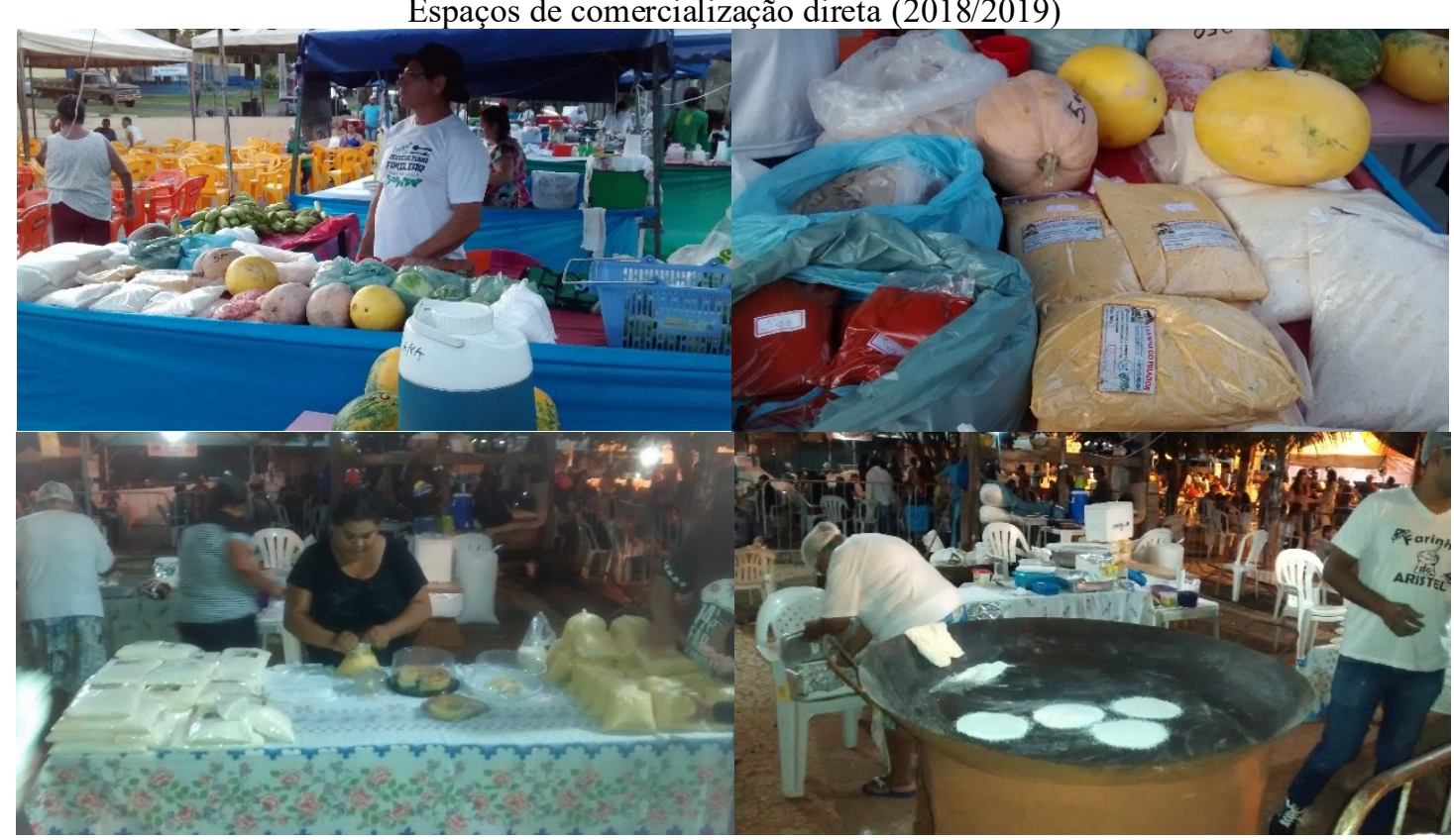

Fonte: Imagens capturadas pela autora.

Os produtores que se utilizam dos circuitos curtos de comercialização são camponeses que trabalham na terra empregando mão de obra familiar. O campesinato produz alimentos para o consumo da família e para a comercialização no mercado local. Uma das características da produção camponesa é a diversidade de alimentos na unidade de produção, tendo em vista a estratégia de reduzir a quantidade de produtos adquiridos no mercado.

Em oposição ao circuito curto, tem-se o circuito longo, que indica uma maior distância entre o produtor e o consumidor. Esse tipo se refere ao modelo do agronegócio que tende a homogeneizar a produção, ocorrendo, principalmente, para atender as demandas do mercado internacional a partir da produção de determinadas commodities. Esse modelo utiliza tecnologia no processo de produção, maquinários agrícolas, intenso uso de agrotóxicos e acontece em grandes unidades de produção.

Além dos danos ambientais da expansão do agronegócio, destacam-se a diminuição de pessoas ocupadas no campo, a expropriação do campesinato e o intenso processo migratório de pessoas do campo para a cidade. Na Tabela 2, apresenta-se o número de pessoal ocupado em estabelecimentos agropecuários, por grupo de área no Brasil. As propriedades de até 50 ha possuem $71,22 \%$ do pessoal ocupado no campo, e no grupo de estabelecimentos de até 10 ha tem-se $41,60 \%$ do pessoal ocupado. Nesses locais, há o predomínio da produção familiar 
camponesa, onde ela trabalha na terra, produzindo alimentos para o autoconsumo e para a comercialização no mercado local.

Os estabelecimentos com mais de 1000 ha possuem 6,85\% do pessoal ocupado no campo. Esses dados enfatizam a importância das unidades de produção camponesa para a manutenção de pessoal no campo, produzindo alimentos que abastecem o mercado local, refletindo, assim, em qualidade de vida para aqueles que vivem no campo.

Tabela 2 - Brasil

Pessoal ocupado em estabelecimentos agropecuários, por grupo de área (2017)

\begin{tabular}{l|r|r}
\multicolumn{1}{c|}{ Grupos de área } & \multicolumn{2}{c}{$\begin{array}{c}\% \text { do total de pessoal } \\
\text { ocupado }\end{array}$} \\
\hline Mais de 0 até menos de 10 há & $\mathbf{6 . 2 5 5 . 2 9 7}$ & $\mathbf{4 1 , 6 0}$ \\
\hline De 10 a menos de 20 ha & $\mathbf{1 . 9 6 8 . 0 8 0}$ & $\mathbf{1 3 , 0 9}$ \\
\hline De 20 a menos de 50 ha & $\mathbf{2 . 4 8 6 . 4 1 9}$ & $\mathbf{1 6 , 5 3}$ \\
\hline De 50 a menos de 100 ha & 1.280 .899 & 8,52 \\
\hline De 100 a menos de 500 ha & 1.541 .719 & 2,40 \\
\hline De 500 a menos de 1000 ha & 361.327 & 6,85 \\
\hline Acima de 1000 há & 1.031 .025 & - \\
\hline Produtor sem área & 112.199 & 100 \\
\hline Total & 15.036 .978 & \\
\hline
\end{tabular}

Fonte: Organizada pela autora com base em IBGE (2018).

Uma outra característica da participação em circuitos curtos de comercialização é o desenvolvimento da autonomia do produtor, pois o camponês define o que será produzido e a sua quantidade, além de selecionar quais produtos receberão algum tipo de beneficiamento e o que será vendido in natura. O camponês escolhe o que será revertido para o autoconsumo e o que será destinado à venda. No caso dos produtores que utilizam os circuitos longos, ocorre a integração da produção a algum tipo de indústria. Esta, por sua vez, definirá o que será produzido, a quantidade e a normatização da produção. Nesse circuito, há a perda da autonomia do produtor.

No Quadro 1, apresentam-se as características dos circuitos curtos e longos de comercialização. Tem-se dois modelos distintos de produção e comercialização, que refletem as características territoriais locais. Nos circuitos curtos ocorre o predomínio de pequenas unidades camponesas que produzem uma diversidade de alimentos; no circuito longo, há o predomínio de grandes e médias unidades que produzem pouca diversidade, em grande quantidade, com intensa utilização de agrotóxicos. 
Quadro 1 - Características dos circuitos de comercialização (2019)

\begin{tabular}{|l|l|}
\hline \multicolumn{1}{|c|}{ Circuitos curtos de comercialização } & \multicolumn{1}{c|}{ Circuitos longos de comercialização } \\
\hline Maior autonomia na produção. & Subordinação da produção à indústria. \\
\hline Maior diversidade na produção. & Produção de apenas um ou poucos produtos. \\
\hline $\begin{array}{l}\text { Maior proximidade entre produtores e e } \\
\text { consumidores. }\end{array}$ & $\begin{array}{l}\text { Vários agentes envolvidos no processo de produção, } \\
\text { transporte, industrialização e comercialização do produto. }\end{array}$ \\
\hline Mão de obra familiar. & Contratação de assalariados. \\
\hline $\begin{array}{l}\text { Utilização de técnicas tradicionais, valorização } \\
\text { da cultura local e do saber-fazer local. }\end{array}$ & Mecanização no processo produtivo. \\
\hline
\end{tabular}

Fonte: Organizado pela autora.

Pode-se destacar vários canais de comercialização que se utilizam de circuitos curtos, e os mais comuns em cidades brasileiras são: as vendas diretas nas chamadas feiras livres, a venda nas residências (o produtor leva a mercadoria até a moradia do consumidor) e a venda na unidade de produção (o consumidor se desloca até a unidade de produção para adquirir o produto); e as vendas indiretas, que se dão com a entrega do alimento do campesinato em comércios e cooperativas. Nesses casos, não é o produtor que comercializa sua produção, temse a figura de um intermediário, porém o consumo tende a ser em âmbito local.

Nessa perspectiva, Leme (2018a; 2018b) ressalta a importância do desenvolvimento de mecanismos na produção e na comercialização como forma de resistência e autonomia do campesinato. Uma das estratégias já pontuadas anteriormente e que deve ser destacada é a diversidade da produção camponesa. Esse é um meio adotado para reduzir o número de itens adquiridos no mercado, visto que a produção camponesa ocorre para o autoconsumo e a venda. Junto a isso, o camponês realiza o beneficiamento de produtos com o objetivo de aumentar sua renda. A comercialização, sendo realizada a partir de circuitos curtos, garante que a renda da produção camponesa seja apropriada pelo próprio campesinato produtor, não sendo transferida para outros setores da sociedade, como ocorre com o modelo imposto pelo agronegócio.

\section{OS CIRCUITOS CURTOS DE COMERCIALIZAÇÃO E A SOBERANIA ALIMENTAR}

De acordo com a organização internacional La Vía Campesina, o conceito de soberania alimentar está em oposição à concepção de segurança alimentar, estabelecida pela Organização das Nações Unidas para a Alimentação e a Agricultura (FAO). Para a organização, entende-se por soberania alimentar:

[...] o direito dos povos a definir suas próprias políticas e estratégias sustentáveis de produção, distribuição e consumo de alimentos, que garantam o direito à alimentação a toda a população, com base na pequena e média produção, respeitando suas próprias culturas e a diversidade dos modos camponeses de produção, de comercialização e de gestão, nos quais a mulher 
desempenha um papel fundamental. Para além disso, é um direito que os povos têm a produzir seus próprios alimentos (BRASIL..., 2016).

No ano de 1996, a FAO realizou a Cúpula Mundial da Alimentação, conferência na qual foram aprovados uma declaração e um plano de ação destinados a combater a fome no mundo. Nessa ocasião, o conceito de segurança alimentar e nutricional foi definido como a forma de garantir a todos condições de acesso a alimentos básicos de qualidade, em quantidade suficiente, de modo permanente e sem comprometer o acesso a outras necessidades essenciais, com base em práticas alimentares saudáveis, contribuindo, assim, para uma existência digna, em um contexto de desenvolvimento integral da pessoa humana (FAO, 1996).

Analisando esses conceitos, entende-se que não basta que um país tenha uma produção de alimentos que atenda sua população ou que essa nação tenha meios para adquirir os alimentos internacionalmente. Para Ramos Filho (2015),

É preciso que cada Nação tenha garantido o direito de manter e desenvolver sua capacidade de produzir alimentos básicos, em consonância e respeito com sua(s) respectiva(s) identidade(s) cultural(s) e produtiva(s), garantindo o direito de produzir o próprio alimento em seu território e afirmando o direito dos povos de ter o controle e exercer o poder sobre suas políticas agrícolas e alimentares (RAMOS FILHO, 2015, p. 59).

A soberania alimentar é muito mais do que o direito à alimentação, é o direito da população de produzir e/ou consumir o que é produzido localmente. A importância da agricultura camponesa é fundamental para a soberania alimentar. Os camponeses trabalham na terra utilizando-se da mão de obra da família, produzem para o consumo próprio e para a venda no mercado local, por meio dos circuitos curtos, a partir de vários canais de comercialização.

A produção camponesa valoriza a produção local, o saber-fazer dos povos da terra e coloca no mercado alimentos de qualidade, sem a utilização de agrotóxicos. Trata-se de um modelo de produção e consumo totalmente contrário ao imposto pelo agronegócio, que possui tendências de homogeneizar os espaços rurais, expropriando ou subordinando camponeses, que deixam de produzir a diversidade de alimentos.

Para Ramos Filho (2015), a soberania alimentar considera o modelo camponês uma referência para o futuro. Dentro dessa perspectiva, o acesso à terra é um elemento fundamental para a soberania alimentar. "O direito ao território é o reconhecimento e a garantia da restituição dos povos originários e tradicionais dos territórios ancestrais” (RAMOS FILHO, 2015, p. 61).

Nesse contexto, entende-se que o papel do Estado é de fundamental importância para garantir o acesso e a permanência na terra. Além disso, torna-se indispensável o 
desenvolvimento de políticas públicas que impulsionem a produção camponesa e a criação de mecanismos que facilitem a comercialização dos produtos do campesinato no mercado local.

Em termos de políticas públicas para o campesinato, tem-se um enorme desafio para os movimentos sociais. Para Ramos Filho (2015), a construção de um projeto de soberania alimentar deve se dar a partir da luta da classe social camponesa, com a imposição de uma política que assegure a produção e o acesso à terra. $\mathrm{O}$ campesinato, enquanto classe, deve rejeitar as políticas de subordinação que atendem o modelo do agronegócio e lutar por políticas emancipatórias, que garantam a reprodução do modo de vida camponês com qualidade. Para Fernandes (2015), a constituição e o estabelecimento de políticas públicas no Brasil se tornaram uma disputa por diversificados modelos de desenvolvimento para o campo: o do agronegócio e o da agricultura camponesa.

\section{O PAPEL dO ESTAdO E dO CAMPESINATO NA CONDUÇÃo de POLÍticas PÚBLICAS PARA A PRODUÇÃO E A COMERCIALIZAÇÃO CAMPONESA}

No Brasil, historicamente, as políticas públicas para o campo têm privilegiado grandes grupos econômicos, em detrimento da produção familiar camponesa. As políticas da agricultura camponesa, quando são estabelecidas, apresentam características voltadas para a integração do campesinato ao mercado capitalista, porém a luta dessas pessoas é por sua emancipação, autonomia na produção e reprodução do modo de vida camponês.

Para Ploeg (2016), o Estado governa as relações econômicas dos meios urbano e rural e suas inter-relações, impondo sua própria marca nelas. Assim, a correlação de forças existentes dentro dessa dinâmica torna-se um elemento crucial para o equilíbrio das relações de poder entre classes com interesses antagônicos, como o campesinato e o agronegócio, sendo que o Estado direcionará suas ações para a classe que possui a hegemonia das relações produtivas. $\mathrm{O}$ equilíbrio entre o Estado e o campesinato é fundamental para a produção de políticas públicas destinadas à agricultura familiar camponesa.

Dessa forma, por meio da ação política de movimentos camponeses, há a criação de políticas públicas voltadas ao campesinato. Para Fernandes (2015), as ações desses movimentos podem ser caracterizadas como política pública; elas não são definidas pelo Estado, mas sim estruturadas pela força dos movimentos sociais. As ocupações de terra na luta pela reforma agrária são exemplares. Para Fabrini (2006), junto à expropriação camponesa e com o 
desenvolvimento do capitalismo no campo, tem-se a construção de possibilidades de retorno ao campo por intermédio das ocupações de terra empreendidas pelos movimentos sociais.

De acordo com Fernandes (2015, p. 22), o modelo de expansão da agricultura capitalista controla as políticas de desenvolvimento do campo. Somente a partir dos últimos anos do século XX e no início no século XXI, os "movimentos camponeses conseguiram influenciar os governos para a criação de planos e políticas públicas" para o campesinato. No que se refere às políticas para produção e comercialização camponesa, merecem destaque o Programa de Aquisição de Alimentos (PAA) e o Programa Nacional de Alimentação Escola (PNAE), criados durante o governo Lula (2003-2011). O PAA e o PNAE colocam a produção camponesa prioritária na comercialização com instituições públicas. O PAA é voltado para o atendimento de entidades beneficentes, e o PNAE é voltado para a merenda escolar.

Atualmente, as propostas de políticas públicas para o campesinato tornaram-se um desafio ainda maior para os movimentos sociais. Após a eleição à Presidência da República de 2018, com a vitória do candidato Jair Bolsonaro (PSL), algumas medidas tomadas logo no início de seu mandato, como o incentivo à utilização de armas de fogo no campo e a criminalização de movimentos sociais, preocupam os representantes desses movimentos.

Entende-se que a luta camponesa no Brasil percorre dois caminhos: o primeiro é o da conquista da terra, e o segundo é para a permanência na terra. Dessa forma, a luta se torna contínua. Após a conquista da terra, o campesinato busca meios para a sua reprodução, enquanto sujeito social, e a produção e a comercialização são fundamentais para isso. Assim sendo, as políticas públicas reivindicadas por movimentos sociais, associações, sindicatos ou entidades devem versar sobre estratégias para a produção e a venda dos alimentos do campesinato, principalmente métodos que coloquem a produção deles como sendo prioritária para a venda no mercado local.

No que concerne à produção, percebe-se que o campesinato necessita de assistência técnica na unidade camponesa. A orientação especializada deve ocorrer de forma a preservar as características da produção familiar camponesa, respeitando as particularidades do modo de vida deles e sua relação com a natureza.

No tocante à comercialização, os camponeses necessitam de auxílio para transporte dos produtos até o mercado, criação de espaço para a venda dos alimentos e facilidades na aquisição da certificação das mercadorias. Além de fortalecer a produção camponesa, essas medidas tornam-se fundamentais para promover a soberania alimentar em âmbito local. 
Para Fabrini (2006), as características do local são essenciais para o desenvolvimento da luta camponesa pelo seu processo de reprodução. Essas lutas podem ir além da atuação dos movimentos sociais, podendo ser construídas a partir de suas práticas cotidianas para a permanência na terra de trabalho. Em um contexto político desfavorável aos movimentos dessa classe, as diferentes práticas do dia a dia transformam-se em táticas para a reprodução camponesa.

Mediante o desenvolvimento de práticas locais, exclusivas do modo de vida camponês, esses sujeitos sociais não ficam reféns de um modelo político que formula suas ações com o objetivo de integrar o campesinato ao sistema, desconsiderando, assim, sua tradição. Estão entre as práticas locais: trocas de produtos entre unidades de produção; produzir uma diversidade de alimentos para reduzir a dependência no mercado local; maximizar a utilização de recursos internos à unidade de produção e diminuir a aquisição de insumos no comércio local; vendas diretas nas residências da área urbana, principalmente quando não são criados locais para a comercialização dos produtos camponeses, entre outras.

Dessa forma, entende-se que o campesinato, organizado em movimentos sociais, possui um papel fundamental para forçar o Estado a desenvolver políticas emancipatórias para o campo. Porém, em momentos de forte repressão das lutas desses sujeitos, quando o Estado passa a desenvolver mecanismos voltados para a expropriação e a proletarização camponesa, cujo objetivo principal é a ampliação das frações territoriais do agronegócio e a redução dos territórios camponeses, esses povos se erguem na luta pela permanência na terra por meio de práticas locais e estratégias para comercialização de seu produto. Assim, além de sua reprodução, eles garantem alimentos para o mercado local.

\section{CONSIDERAÇÕES FINAIS}

No Brasil, verifica-se um grande número de unidades camponesas de produção. Elas possuem a maior parte do pessoal empregado no campo brasileiro. Uma das características do campesinato é uma produção voltada a atender o mercado local. A utilização dos circuitos curtos de comercialização permite que o produto deles seja vendido a partir de relações sociais favoráveis tanto para o produtor (camponês) como para o consumidor.

A participação desses sujeitos sociais no processo de construção das políticas públicas se dá pela luta junto aos movimentos sociais. Entende-se que o Estado, na formulação de suas 
ações, exclui qualquer possibilidade de atendimento ao campesinato. Logo, a luta por políticas públicas é a principal reivindicação dos movimentos.

Porém, o Estado pode criar mecanismos para combater o exercício dos movimentos, provocando a diminuição ou a extinção de suas atividades. Entende-se que nos momentos de repressão, os camponeses são capazes de desenvolver várias estratégias para seu contínuo processo de reprodução; técnicas que somente o mundo camponês possui de criar e de se recriar.

\section{REFERÊNCIAS}

BAPTISTA, Alberto et al. Recomendações de medidas de política de apoio aos circuitos curtos agro-alimentares: período de programação 2014-2020 (Relatório Preliminar), ISA, UE, UTAD, jun. 2013.

BRASIL: Soberania Alimentar deve ser debatida pelo conjunto da sociedade. La Vía Campesina, 18 out. 2016. Disponível em: https://cloc-viacampesina.net/brasil-soberaniaalimentar-deve-ser-debatida-pelo-conjunto-da-sociedade. Acesso em: 14 maio 2019.

DAROLT, Moacir Roberto. Mercados locais, circuitos curtos e novas relações produçãoconsumo. In: NIERDELE, Paulo André; ALMEIDA, Luciano de; VEZZANI, Fabiane Machado. Agroecologia: práticas, mercados e políticas para uma nova agricultura. 1. ed. Curitiba, PR: Kairós, 2013. p. 139-170.

FABRINI, João Edmilson. A escala da luta e resistência camponesa. Geosul, Florianópolis, v. 21, n. 42, p. 63-91, jul./dez. 2006.

FAO. Declaração de Roma sobre a segurança alimentar mundial. Roma: FAO, 1996. Disponível em: http://www.fao.org/docrep/003/W3613P/W3613P00.htm. Acesso em: 14 maio 2019.

FERNANDES, Bernardo Mançano. Políticas Públicas e questão agrária: bases para o desenvolvimento territorial camponês. In: RAMOS FILHO, Eraldo da Silva et al. (org.). Políticas públicas e território. 1. ed. São Paulo, SP: Outras Expressões, 2015. p. 17-37.

IBGE. Censo Agropecuário 2017. Rio de Janeiro, RJ: IBGE, 2018. Disponível em https://sidra.ibge.gov.br/pesquisa/censo-agropecuario/censo-agropecuario-2017. Acesso em: 14 maio 2019.

LEME, Simone Maria. As estratégias de resistência camponesa na contemporaneidade: uma análise dos camponeses da Colônia Pulador em Anastácio-MS. Campo-território: Revista de Geografia Agrária, v. 13, n. 30, p. 92-112, ago. 2018a.

LEME, Simone Maria. Desenvolvimento de mecanismos de comercialização como forma de resistência e autonomia camponesa. Cadernos de Agroecologia, [s. l.], v. 13, n. 2, dez. 2018b.

MARTINS, José de Souza. Os camponeses e a política no Brasil. 4. ed. Petrópolis, RJ: Vozes, 1990.

MARX, Karl; ENGELS, Friedrich. A ideologia alemã. Tradução de Luis Claudio de Castro Costa. São Paulo, SP: Martins Fontes, 1998a.

MARX, Karl; ENGELS, Friedrich. O Manifesto Comunista. Tradução de Álvaro Pina. São Paulo, SP: Editora Boitempo, 1998b. 
OLIVEIRA, Ariovaldo Umbelino de. A agricultura camponesa no Brasil. São Paulo, SP: Contexto, 1991.

OLIVEIRA, Ariovaldo Umbelino de. A geografia agrária e as transformações territoriais recentes no campo brasileiro. In: CARLOS, Ana Fani A. (org.). Novos caminhos da geografia. São Paulo, SP: Contexto, 1999. p. 63-107.

PLOEG, Jan Douwe van der. Camponeses e a arte da agricultura: um manifesto chayanoviano. Tradução de Claudia Freire. 1. ed. São Paulo, SP: Editora Unesp; Porto Alegre, RS: Editora UFRGS, 2016.

RAMOS FILHO, Eraldo da Silva. O campesinato entre a segurança e a soberania alimentar. In: RAMOS FILHO, Eraldo da Silva et al. (org.). Políticas Públicas e território. 1. ed. São Paulo, SP: Outras Expressões, 2015. p. 40-64. 